\title{
Chromosome polymorphisms in natural populations of the South American grasshopper Sinipta dalmani
}

\author{
Maria Isabel Remis \\ Departamento de Ecología, Genética y Evolución, Facultad de Ciencias Exactas y Naturales, \\ Universidad de Buenos Aires, Buenos Aires, Argentina.
}

\begin{abstract}
Six populations of Sinipta dalmani from the provinces of Buenos Aires and Entre Rios (Argentina) were analyzed. The populations of "El Palmar" National Park (Entre Rios) were polymorphic for pericentric inversions in pairs M4 and M7 and for a centric fusion involving pair M5 and the X chromosome. The M4 inversion remained similar over time and the karyomorphic frequencies did not depart from those expected according to the Hardy-Weinberg equilibrium. The analysis of chiasma frequency and distribution showed clear intra- and interchromosome effects of the different chromosome rearrangements. Both inversions and centric fusions were related with total or partial crossing over restriction in heterozygous condition, leading to a genetic differentiation between rearranged and non-rearranged chromosomes. The chromosome polymorphisms analyzed herein were associated with an increase in the number of terminal chiasmata both in the rearranged chromosomes (heterozygous centric fusion and homozygous M4 inversion) and in the other chromosomes (M4 inversion). Our results showed that the chromosome polymorphisms in $S$. dalmani may be associated with a significant decrease in genetic recombination, which may explain in part their maintenance in some areas of its geographical distribution.
\end{abstract}

Key words: pericentric inversion, centric fusion, chiasma conditions, grasshopper.

Received: April 19, 2007; Accepted: August 6, 2007.

\section{Introduction}

Chromosome polymorphisms are a predominant feature in Orthoptera. These chromosome rearrangements are usually associated with effects on chromosome pairing, chiasma frequency and/or distribution and fertility (Hewitt, 1979; Jones and Rees, 1982; John, 1983). Polymorphisms for pericentric inversions and centric fusions are particularly associated with restrictions in chiasma formation, which prevents recombination in certain genome regions and ensures normal meiosis (White, $1951 \mathrm{a}$; b; White and Morley, 1955; John and Hewitt, 1970; Weissman, 1976; de Vaio et al., 1979; Goni et al., 1985; Colombo, 1987; 1989b; Confalonieri, 1988). Moreover, structural chromosome polymorphisms may affect chiasmata in non-rearranged chromosome pairs, resulting in different levels of recombination according to the frequency of the rearrangements (White and Morley, 1955; Weissman, 1976; Cabrero and Camacho, 1982).

Send correspondence to Maria Isabel Remis. Laboratorio de Genética de Poblaciones, Departamento de Ecología, Genética y Evolución, Facultad de Ciencias Exactas y Naturales, Universidad de Buenos Aires, 1428 Buenos Aires, Argentina. E-mail: mariar@ege. fcen.uba.ar.
Sinipta dalmani is a South-American grasshopper species in which polymorphisms for pericentric inversions and a centric fusion were described in populations collected at the "El Palmar" National Park (Entre Rios province) (Remis, 1989; 1990). In the present work six populations from the Entre Rios and Buenos Aires provinces were analyzed. The stability of the rearrangements and their influence on genetic recombination (estimated through chiasma frequency and distribution) were analyzed. The relevance of these features for the genetics of this species is discussed.

\section{Material and Methods}

Samples of Sinipta dalmani adults were collected from six populations located in eastearn Argentina from 1986 to 1994. Samples came from four populations of "El Palmar" National Park (Los Loros (LL), Los Sauces (LS), El Camino (EC), El Palmar (EP)), from one Gualeguaychú population (GU) located in the Entre Rios province, and from one Puerto Talavera population (PT) in the Buenos Aires province.

\section{Cytogenetic analysis}

Male testes were removed and fixed in 3:1 absolute ethanol : acetic acid at $4{ }^{\circ} \mathrm{C}$. Cytological preparations were 
obtained through the squashing of follicles in propionic haematoxylin. Population cytogenetic analyses were performed using wild individuals from LL populations collected during 1986, 1987 and 1988. A minimum of ten cells at metaphase I per individual were studied and chiasmata were classified as proximal, interstitial and distal according to centromere position. In order to assess the cytogenetic effects of chromosome rearrangements, we analyzed chiasma frequency and distribution from samples obtained in the present study and from one previously reported population (LL1986 for M4 inversion and LL1987 for centric fusion) (Table 1).

\section{Chromosome differentiation}

Chromosome differentiation was evaluated according to Wright (1951) as modified by Nei (1977) in terms of observed heterozygosity. The $\mathrm{F}_{\mathrm{ST}}$ coefficient was estimated by the method of Nei and Chesser (1983) to accommodate the size of each sample.

\section{Results}

\section{Standard karyotype and chromosome rearrangements}

The male karyotype of Sinipta dalmani is composed of 23 acrocentric chromosomes $(22+\mathrm{X} 0)$. The autosomes may be grouped in three large (L1-L3), five medium (M4M8) and three small (S9-S11) chromosomes pairs (Figure 1A) (Bidau, 1984; Remis, 1989; 1990). In the populations of "El Palmar" National Park (Entre Ríos province), two pericentric inversions, involving pairs M4 and M7, and a centric fusion were detected (Figure 1B, C and D). The

Table 1 - Inversion M4 frequencies (i) in six Sinipta dalmani populations from Entre Ríos and Buenos Aires provinces showing the number of analysed males $(\mathrm{N})$ and $\mathrm{X}^{2}$ values of fit and goodness test. LL: Los Loros, EP: El Palmar, LS: Los Sauces, EC: El Camino, GU: Gualeguaychú.

\begin{tabular}{lcclcc}
\hline & & $\mathrm{N}$ & $\mathrm{i}$ & $\mathrm{X}^{2}$ & $\mathrm{p}$ \\
\hline LL & 1986 & 30 & $0.40^{*}$ & 0.83 & 0.36 \\
& 1987 & 38 & 0.27 & 0.13 & 0.72 \\
& 1988 & 55 & $0.38^{* *}$ & 2.92 & 0.09 \\
& 1992 & 47 & 0.32 & 0.02 & 0.98 \\
& 1994 & 27 & 0.22 & 1.19 & 0.50 \\
\hline EP & 1986 & 22 & $0.30^{*}$ & 0.88 & 0.35 \\
\hline LS & 1988 & 30 & $0.37^{* *}$ & 0.57 & 0.45 \\
\hline EC & 1988 & 31 & 0.23 & 0.19 & 0.66 \\
& 1992 & 111 & $0.28^{* *}$ & 1.22 & 0.54 \\
\hline GU & 1988 & 10 & - & - & - \\
& 1989 & 11 & - & - & - \\
\hline IT & 1987 & 18 & - & - & - \\
\hline
\end{tabular}

*Data from Remis 1989.

**Data from Remis 1997 and the present work.

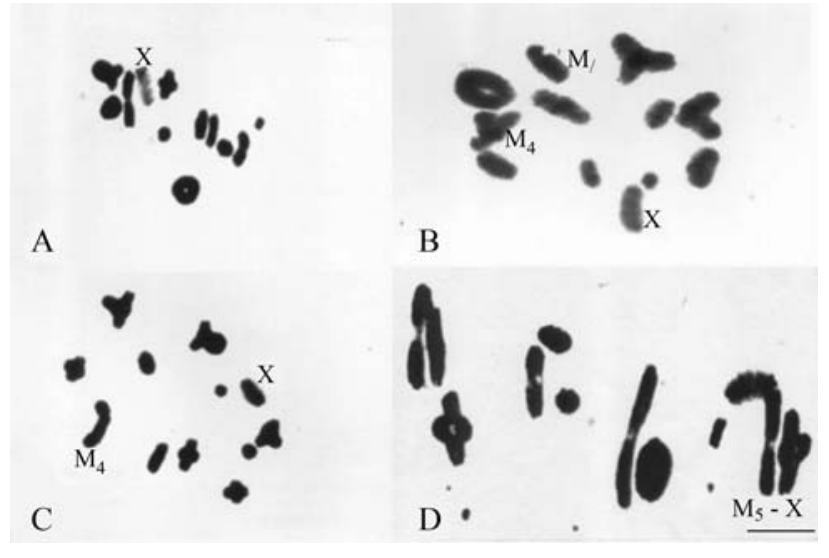

Figure 1 - A- Metaphase I of the standard karyotype of Sinipta dalmani. B- Metaphase I of a double heterozygote for a pericentric inversions in pairs M4 and M7. C- Metaphase I of a M4 inversion homozygote. DMetaphase I of a heterozygote for the centric fusion showing the neoXY bivalent (M5-X). Bar: $10 \mu \mathrm{m}$.

pericentric inversions changed acrocentric chromosomes into submetacentrics. The centric fusion involved pair M5 and the X chromosome (Remis, 1990).

\section{Inversion polymorphism frequencies}

The M4 inversion was found in all populations from the National Park: "Arroyo Los Loros" (LL), "Arroyo El Palmar" (EP), "Los Sauces" (LS) and "El Camino" (EC). This rearrangement was not detected in the samples from Gualeguaychú (from the same province) and Puerto Talavera (Buenos Aires province)

A total of 430 males were analyzed between 1986 and 1992 (Table 1). Temporal variation was evaluated in the LL population considering the chromosome data obtained along five years. The frequency of inversion M4 remained similar in the LL population through time $\left(\mathrm{X}_{4}^{2}: 6.55\right.$, $p=0.68)$. The observed karyomorphic frequencies did not depart significantly from the Hardy-Weinberg equilibrium in all the samples analyzed (Table 1).

The $\mathrm{F}_{\mathrm{ST}}$ coefficient was low and a homogeneity test did not reveal significant differences in the frequency of M4 inversion between sampled populations $\left(\mathrm{X}^{2}: 4.65\right.$, $p=0.09)$. The $X^{2}$ value, however, was marginally significant as a consequence of the low frequency of the M4 inversion in EC. The frequency of the inversion in the LL and LS populations did not differ but there were significant differences with respect to the EC population $\left(X^{2}: 4.40\right.$, $\mathrm{p}=0.035)$.

\section{Effects of pericentric inversions on chiasma frequency and distribution}

A cytogenetic study performed in the LL population revealed that the M4 inversion was associated with significant effects on chiasmata (Remis, 1989). The inversion in M4 precluded crossing over within its limits in heterozygotes and decreased interstitial chiasma frequency in the 
homozygous condition. There was also indication that crossing over was restricted in the other chromosome pairs.

In order to better understand the intraspecific chromosome variation, the intra- and interchromosome effects of the M4 inversion were analyzed in three samples of the LL population collected at different times. The interstitial (Xi) and total (XT) chiasma frequencies were scored in all three karyomorphs and their frequencies in pair M4 and in the other chromosomes are shown in Table 2.

There were significant differences in the mean $\mathrm{Xi}$ and XT among karyomorphs (Table 2a). The analysis in M4 showed significant XT differences among karymorphs (Table $2 b$ ), with the inversion homozygotes presenting the highest XT values. There were also highly significant differences in the percentage of interstitial chiasmata $(\mathrm{Xi})$ in M4 $\left(\mathrm{X}^{2}=64.21, \mathrm{p}<10^{-4}\right)$. Heterozygotes displayed the highest Xi values which may be explained by the absence of chiasmata within the limits of the inversion and by their increase in the adjacent regions. Inversion homozygotes showed a reduction in the number of interstitial chiasmata and a terminal distribution of chiasmata was evident. When M4 data were excluded from the analysis the Xi varied among karyomorphs whereas XT remained similar (Table 2c).

In order to study the interchromosome effect, the distribution of chiasmata in each chromosome pair was analyzed in the three M4 karyomorphs. An increase of $\mathrm{Xi}$ in the M5-M6 and M7-M8 pairs was evident in M4 inversion carriers (Figure 2). Highly significant differences in terminal chiasma frequency $(\mathrm{Xt})$ were found among karyomorphs when M5-M6 data were analyzed over three consecutive years $\left(X^{2}: 19.14, p: 0.0007\right)$. Only the 1986 sample showed significant differences in Xt among karyomorphs when the M7-M8 pairs were considered ( $X^{2}: 7.42$, p: 0.024). Similarly, the $\mathrm{S} 10$ and $\mathrm{S} 11$ bivalents show an increase in $\mathrm{Xt}$ in inversion carriers $\left(X^{2}: 6.24\right.$, p: $0.04 ; X^{2}: 12.65, p: 0.0018$ respectively) (Figure 2).

Table 2 - Interstitial (Xi) and total (XT) chiasmata frequencies in different M4 inversion karyomorphs of Sinipta dalmani from the "Los Loros" population and "F" statistics values for the comparison of averages among different karyomorphs. a) mean frequencies, b) frequencies in M4 pair, c) frequencies without M4 data. S/S: standard homozygotes, S/I: heterozygotes, I/I: inversion homozygotes. (N: number of analyzed individuals; $n$ : number of analyzed cells).

\begin{tabular}{|c|c|c|c|c|c|}
\hline & $\mathrm{S} / \mathrm{S}$ & $\mathrm{S} / \mathrm{I}$ & $\mathrm{I} / \mathrm{I}$ & $\mathrm{F}$ & $\mathrm{P}$ \\
\hline $\mathrm{N}$ & 27 & 24 & 13 & & \\
\hline $\mathrm{n}$ & 293 & 246 & 135 & & \\
\hline \multirow{2}{*}{ a) $\begin{array}{l}X \\
X\end{array}$} & 3.99 & 4.31 & 3.19 & 18.3 & $<10^{-4}$ \\
\hline & 12.30 & 12.24 & 12.73 & 3.86 & 0.02 \\
\hline \multirow[t]{2}{*}{ b) $\mathrm{X}$} & $45 \%$ & $63 \%$ & $18 \%$ & & \\
\hline & 1.05 & 1.00 & 1.21 & 25.3 & $<10^{-4}$ \\
\hline \multirow[t]{2}{*}{ c) $\mathrm{Xi}$} & 3.51 & 3.61 & 2.99 & 4.92 & 0.01 \\
\hline & 11.24 & 11.26 & 11.54 & 1.69 & 0.19 \\
\hline
\end{tabular}

The M7 inversion carrier males were always S/I for the M4 inversion. In order to analyze the influence of the M7 inversion, chiasma frequency and distribution were studied in these males and in ten S/S M7 individuals (also S/I for the M4 inversion) (Table 3). In both populations there were no significant differences in Xi and XT among karyomorphs. The M7 bivalent always had a single chiasma, which could be located in a proximal (Xp), interstitial or, more frequently, in a distal position. The chiasma was never located in a proximal region in the heterozygotes (Table 3) but no significant differences were detected because of the low proximal chiasma frequency in S/S individuals.

\section{Fusion polymorphism frequencies}

The centric fusion was detected in the LL, LS and EC populations (Table 4). In the LL population, this rearrangement was studied over three consecutive years and its frequency did not significantly vary through time $(\mathrm{p}>0.05)$. The centric fusion was also detected in two other populations collected in 1988 (LS and EC). There were no differences in centric fusion frequency among the three populations $(\mathrm{p}>0.05)$.

Table 3 - a) Interstitial (Xi) and total (XT) chiasma frequencies in standard homozygotes $(\mathrm{S} / \mathrm{S})$ and heterozygotes for the M7 inversion $(\mathrm{S} / \mathrm{I})$ of the 1988 "Los Loros"(LL) and "Los Sauces" (LS) populations (n: number of analyzed cells). b) Chiasma distribution (percentage) in the M7 bivalent (P: proximal, I: interstitial, D: distal).

\begin{tabular}{lccc}
\hline & & $\mathrm{S} / \mathrm{S}$ & $\mathrm{S} / \mathrm{I}$ \\
\hline a) & $\mathrm{n}$ & 50 & 20 \\
$\mathrm{LL}$ & $\mathrm{Xi}$ & 3.1 & 3.9 \\
& $\mathrm{XT}$ & 12.5 & 11.6 \\
\hline & $\mathrm{n}$ & 50 & 21 \\
$\mathrm{LS}$ & $\mathrm{Xi}$ & 3.16 & 3.33 \\
& $\mathrm{XT}$ & 12.3 & 12.71 \\
\hline b) & $\mathrm{n}$ & 106 & 40 \\
& $\mathrm{P}$ & 1 & - \\
& $\mathrm{I}$ & 14 & 25 \\
& $\mathrm{D}$ & 85 & 75 \\
\hline
\end{tabular}

Table 4 - Fusion (f) frequencies in different karyomorphs of Sinipta dalmani males from the "Los Loros" (LL), "Los Sauces" (LS) and "El Camino" (EC) populations.

\begin{tabular}{ccccc}
\hline & & XO & neoXY & f \\
\hline \multirow{3}{*}{ LL } & 1986 & 29 & 1 & 0.033 \\
& $1987^{*}$ & 33 & 5 & 0.131 \\
\hline EC & 1988 & 52 & 3 & 0.054 \\
\hline LS & 1988 & 30 & 1 & 0.032 \\
\hline
\end{tabular}

*Data from Remis, 1990. 

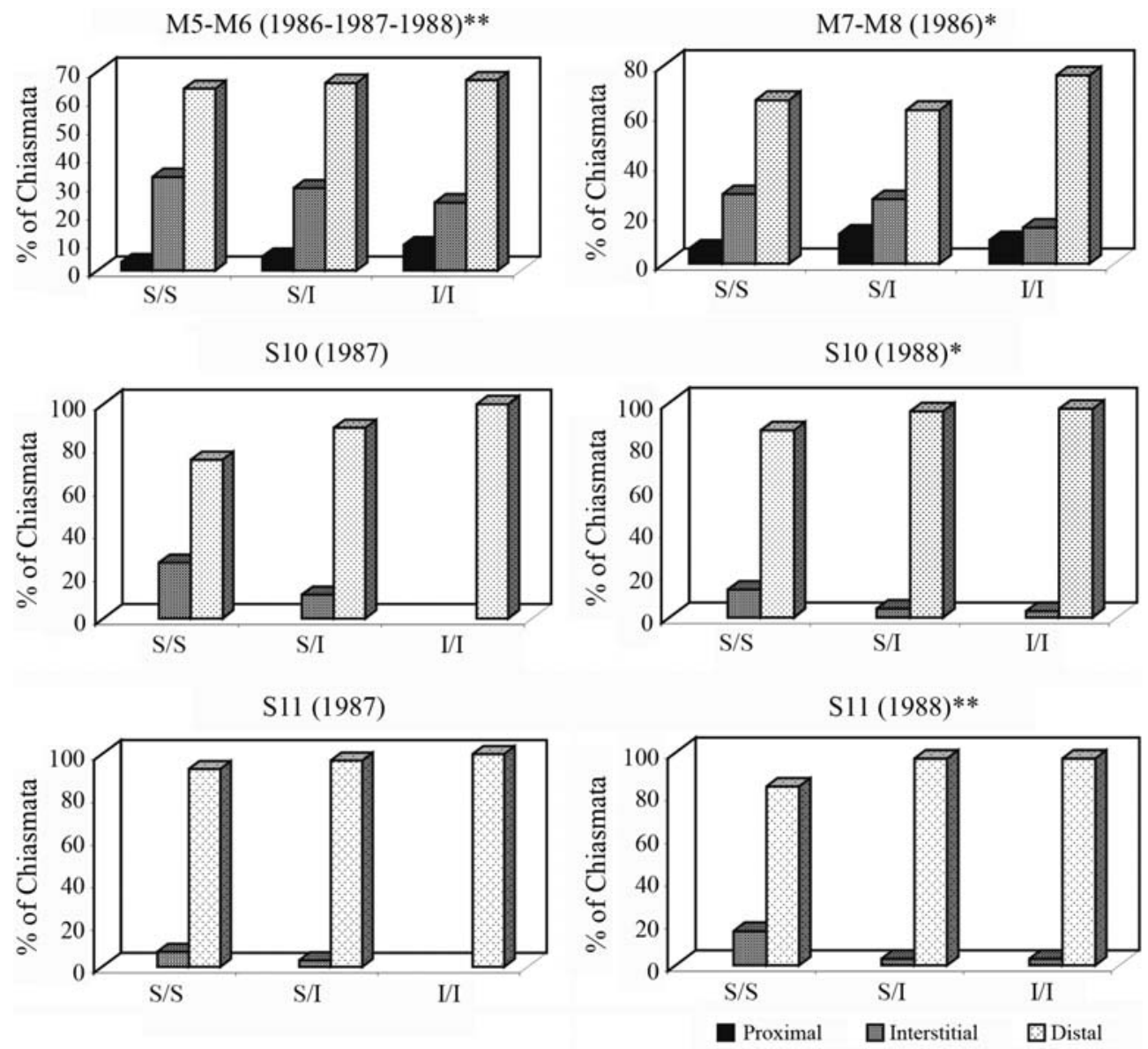

Figure 2 - Chiasma distribution patterns in medium (M) and small (S) pairs of standard homozygotes (S/S), heterozygotes (S/I) and homozygotes for the M4 inversion in Sinipta dalmani.

\section{Effects of centric fusion on chiasma frequency and distribution}

In the present paper the standard $(\mathrm{X} 0)$ and fused males (neoXY) collected in 1986 and 1988 were analyzed. The results presented here corroborate a previous report that showed a significant reduction in the mean $\mathrm{Xi}$ frequency in individuals bearing the centric fusion (Remis 1990). This is explained by a reduction in the number of interstitial chiasmata in the rearranged chromosomes since the exclusion of M5 data from the analysis did not reveal any significant differences (Table 5).

\section{Discussion}

Orthoptera is the animal group where chromosome polymorphisms have been more frequently reported (Hewitt, 1979; Jones and Rees, 1982; John, 1983). A chromosome rearrangement may directly affect the rates and/or the patterns of crossing over events along chromosomes (i.e. John and Hewitt, 1970 Goñi et al., 1985 Weissman, 1976; Cabrero and Camacho, 1982). Studies in mammals and plants demonstrated that chiasma frequency and distribution may be considered as a good indicator of the rates and patterns of genetic recombination (Anderson et al., 1999; King et al., 2002). Chromosome rearrangements with effects on chiasma frequency and distribution may affect the level of genetic recombination. In particular, polymorphisms for pericentric inversions and centric fusions are generally associated with striking effects on genetic recombination (Brussard, 1984).

In Sinipta dalmani, pericentric inversions in pairs M4 and $\mathrm{M} 7$ prevent crossing over within the inverted segments in the heterozygous conditions. In Trimerotropis pallidipennis, T. pseudofasciata, T. suffusa and Aiolopus strepens, it was also demonstrated that chiasmata do not occur in the inverted regions of the inversion heterozygotes (Vaio et al., 1979; Weissman, 1976; White and Morley, 1955; Cabrero and Camacho, 1982 respectively). This intrachromosomal effect on chiasmata may contribute to ensure a normal meiotic behavior without affecting the fertility of carriers since it prevents the formation of unbalanced crossing over products.

In the case of the X-M5 centric fusion, the neoXY bivalent always showed an increase in distal chiasma frequency although there is no physical constraint for chiasmata formation. Hence, in addition to the direct effect of 
Table 5 - Mean interstitial (Xi) and total (XT) chiasma frequencies from Sinipta dalmani males with different karyomorphs for the M5-X fusion with and without the data of the M5 pair in two samples of the Los Loros population. F: statistic value for the comparison of averages among karyomorphs. (n: number of analyzed cells).

\begin{tabular}{|c|c|c|c|c|c|c|c|c|c|}
\hline & & \multicolumn{4}{|c|}{ With M5 pair } & \multicolumn{4}{|c|}{ Without M5 pair } \\
\hline & & neoXY & X0 & $\mathrm{F}$ & $\mathrm{p}$ & neoXY & $\mathrm{X} 0$ & F & $\mathrm{p}$ \\
\hline \multirow{3}{*}{1987} & $\mathrm{n}$ & 90 & 117 & & & 90 & 117 & & \\
\hline & $\mathrm{Xi}$ & 3.31 & 4.09 & 5.8 & 0.037 & 3.22 & 3.66 & 2.59 & 0.13 \\
\hline & XT & 11.90 & 12.19 & 0.2 & 0.704 & - & - & - & - \\
\hline \multirow{3}{*}{1988} & $\mathrm{n}$ & 45 & 66 & & & 45 & 66 & & \\
\hline & $\mathrm{Xi}$ & 3.16 & 4.03 & 10.55 & 0.02 & 3.11 & 3.68 & 3.56 & 0.10 \\
\hline & XT & 12.06 & 12.20 & 0.59 & 0.47 & - & - & - & - \\
\hline
\end{tabular}

reducing the number of independent linkage groups, the centric fusion also limited recombination within the fused M5 chromosome. Several examples in Orthoptera showed that autosomal centric fusions can modify the patterns of intrachromosome chiasma frequency and distribution to ensure the correct orientation of multivalents during meiosis (Hewitt and Schroeter, 1968; Bidau and Mirol, 1988; Colombo, 1989b). Nevertheless, centric fusion polymorphisms involving sex chromosomes are not frequent in Orthoptera (John, 1983). Two chromosomically distinct European populations of the grasshopper Podisma pedestris were described: X0/XX or neo XY/neoXX (John and Hewitt, 1970; Hewitt and John, 1972). The polymorphism for this rearrangement appears to be restricted to a narrow hybrid zone (John, 1983). The neoXY males exhibited a considerable restriction in proximal chiasma formation (John and Hewitt, 1970), which is in agreement with the results herein presented.

The heterozygous forms of both rearrangements displayed a similar intrachromosome effect associated with a redistribution of chiasmata since the total chiasma frequencies remained similar to that of standard individuals in all cases. Thus, both inversions and centric fusions were related with total or partial intrachromosome restriction in crossing over, leading to a genetic differentiation between rearranged and non-rearranged chromosomes.

Additionally, the M4 inversion exhibited an intrachromosome effect in homozygotes. The intrachromosome recombination pattern was modified by a change in the number of chiasmata, which were significantly distributed in a terminal position. Similar results were detected in Trimerotropis pallidipennis, where the terminal chiasma frequency significantly increased in populations with a high frequency of I/I with two terminal chiasmata (Vaio et al., 1979; Goñi et al., 1985). The number of chiasmata per bivalent depends on several factors such as chromosome size, sequence content, chiasma interference and centromere-telomere polarity (Dumas and Britton-Davidian, 2002 and references therein). Whatever the reason, this effect allows increasing the genetic exchange in the rearranged chromosome pair and thus genetic variability. Burt
(2000) pointed out that changes in the number of crossing over events have larger effects on genetic variability than those modifying diploid number.

The effects of chromosome rearrangements on chiasma frequency and distribution in other chromosomes of the complement were also reported (White and Morley, 1955; Cabrero and Camacho, 1982; Colombo, 1989b; Remis, 1989). In T. suffusa and T. pseudifasciata, the reduction in chiasma frequency in the inversion heterozygous pair is compensated by an increase in chiasma frequency in other chromosomes of the complement (White and Morley, 1955; Weissman, 1976). This compensatory effect was not detected in T. pallidipennis in which the number of heterozygous bivalents per individual was negatively associated with a decrease in mean chiasma frequency (Vaio et al., 1979; Goñi et al., 1985). In Aiolopus strepens, heterozygotes for a pericentric inversion in pair S11 showed higher terminal chiasma frequencies in the remaining pairs in relation to standard homozygotes (Cabrero and Camacho, 1982). In Sinipta dalmani, an interchromosome effect was also detected. The analysis of chiasma frequency and distribution over three consecutive years showed that the M4 inversions produced an increase in terminal chiasma frequency in the medium and/or small pairs in both the heterozygous and specially in the homozygous condition. Thus, the M4 inversions may also be considered as partial suppressors of interstitial crossing over in the rest of the complement.

The present study represents an extensive report on chiasma conditions in chromosomally polymorphic populations of $S$. dalmani. The results presented herein are in agreement with previous data and show the existence of clear intra- and interchromosome effects of different chromosome rearrangements on chiasma formation. These effects may lead, in some cases, to the occurrence of recombination in regions of the standard homozygotes not usually involved in recombination. Consequently, the overall linkage disequilibrium in polymorphic populations would be drastically altered in relation to monomorphic populations. Moreover, the chromosome polymorphisms analyzed herein were associated with an increase in the number of 
terminal chiasmata both in the rearranged chromosomes (heterozygous centric fusion and homozygous M4 inversion) and in the other chromosomes (M4 inversion). Terminal chiasmata lead to exchanges of shorter fragments reducing the efficiency of genetic recombination (Dumas and Britton-Davidian, 2002). In S. dalmani chromosome polymorphisms may be associated with a significant decrease in genetic recombination.

The study of the LL population during five years from 1986 to 1994 indicated that the M4 inversion seemed to be temporally stable suggesting an adaptive role for this polymorphism. The study of the different populations sampled within the National Park (LL, LS and EC) in 1998 also allowed the evaluation of chromosome differentiation within this region. The slight chromosome differentiation could be attributed to the low frequency of inversions in the EC population. The M7 inversion was detected at low frequencies in a heterozygous condition in two out of the four analyzed populations (LL and LS) and in one of them (LL) in the samples collected in the last two years. This inversion should thus be considered as polymorphic (at $1 \%$ level).

The centric fusion involving the sex chromosome is present in a polymorphic state (Remis 1990), a very rare situation in Orthoptera, although there are several instances in which fixed X/A fusions allow the distinction between related Orthoptera races or species (Hewitt, 1979). The frequency of the fusion in the different samples of $S$. dalmani was low and there were no statistical differences neither among populations nor among years. This fusions was associated both with an increase in terminal chiasma frequency in the fused pair (this work) and with a decrease in the frequency of functional sperm (Remis 1993). Thus, based on the temporal stability, the influence on sperm formation and the particular effect on genetic recombination, it is tempting to suggest a non-neutral explanation for the maintenance of this fusion at a low frequency.

Among all the populations of $S$. dalmani so far described, only those from the "El Palmar" National Park were polymorphic for chromosome rearrangements. Populations from Puerto Talavera, Gualeguaychú and the populations from "Pereyra Iraola" Park (Buenos Aires province) and "Ruta Nacional n. 3, km 1059 (Rio Negro province) reported by Bidau $(1984 ; 1988)$ did not present structural rearrangements. However, a polymorphism for a minute B chromosome was found in the Ruta Nacional population. This type of supernumerary chromosome may indicate the previous existence of chromosome rearrangements, which could have played a role in their origin without being retained in the population.

It is generally assumed that recombination modifies the fitness of carriers through the production of recombinant progenies. In this scenario one is tempted to hypothesize that chromosome rearrangements may be maintained in some areas of the geographical distribution of this spe- cies as it is related with remarkable effects on genetic recombination and thus on the genetic variability.

In the last years, we detected an association of the M4 inversion with a significant decrease in several morphometric traits that are selected during the adult stage (Remis, 1997; Remis et al., 2000; Remis, 2002; Pensel and Remis, 2007). The uni- and multivariate analysis of sexual selection in males revealed that this rearrangement is negatively selected during mating (Remis et al., 2000). The M4 temporal stability detected in the present paper suggests that selection may be acting in another fitness component counterbalancing the previously detected negative effect.

Our results showed that $S$. dalmani exhibits chromosome variation in some areas of its geographic distribution, reflecting the action of evolutionary and/or historical factors. Although the effects of the M4 inversion on chiasma conditions and fitness were documented, the relative contribution of non-selective forces in shaping the observed chromosome pattern should be stressed in further studies.

\section{Acknowledgments}

Funding provided by CONICET (PIP 5198) and Universidad de Buenos Aires (X-309/04) through grants to Dr. M.I. Remis are gratefully acknowledged.

\section{References}

Anderson LK, Reeves A, Webb LM and Ashley T (1999) Distribution of crossing over on mouse synaptonemical complexes using inmunofluorescens localization of Mlh 1 protein. Genetics 151:1569-1579.

Bidau JC (1984). Estudios citogenéticos en Orthoptera de Sudamerica. Tesis Doctotal, Universidad de Buenos Aires, Buenos Aires.

Bidau JC (1988) Micro and macrospermatids production induced by meiotically unstable B-chromosomes in two species of grasshoppers (Acrididae). Rev Bras Genet 11:547-561.

Bidau JC and Mirol PM (1988) Orientation and segregation of Robertsonian trivalents in Dichroplus pratensis (Acrididae). Genome 30:947-955.

Brussard PF (1984) Geographic patterns and environtmental gradients: The central-marginal model in Drosophila revisted. Ann Rev Ecol Sust 15:25-64.

Burt A (2000) Perspective: Sex, recombination, and the efficacy of selection - was Weismann right? Evolution 54:337-351.

Cabrero J and Camacho JPM (1982) Pericentric inversion polymorphism in Aiolopus strepens (Orthoptera, Acrididae): Effects on chiama formation. Caryologia 35:411-424.

Colombo PC (1987) Effects of centric fusions on chiasma frequency and position in Leptysma argentina. I. Spontaneous and stable centric fusions. Genetica 72:171-179.

Colombo PC (1989a) Effects of B-chromosomes on recombination in Cylindrotettix obscurus (Leptysminae, Acrididae). Caryologia 42:65-79.

Colombo PC (1989b) Chromosome polymorphisms affecting recombination and exophenotypic traits in Leptysma argentina (Orthoptera): A populational survey. Heredity 62:289299. 
Confalonieri VA (1988) Effects of centric-shift polymorphisms on chiasma conditions in Trimerotropis pallidipennis. Genetica 76:171-179.

Dumas D and Britton-Davidian J (2002) Chromosomal rearrangements and evolution of recombination comparison of chiasma distribution patterns in standard and Robertsonian populations of the house mouse. Genetics 162:1355-1366.

Goni B, De Vaio ES, Beltrami M, Leira MS, Crivel M, Panzera F, Castellanos P and Basso A (1985) Geographic patterns of chromosomal variation in populations of the grasshopper Trimerotropis pallidipennis from southern Argentina. Can J Genet Cytol 27:50-271.

Hewitt GM (1979) Orthoptera: Grasshoppers and Crickets. Animal Cytogenetics v. 3. Gerbruder Borntraeger, Berlin, p. 170

Hewitt GM and Schroeter GL (1968). Population cytology of the genus Oedaleonotus. I. The karyotypic facies of Oedaleonotus enigma. Chromosoma 25:121-140.

Hewitt GM and John B and (1972) Interpopulation sex chromosome polymorphism in the grasshopper Podisma pedestris: II. Population parameters. Chromosoma 37:23-42.

John B (1983) The role of chromosome change in the evolution of orthopteroid insects. In: Sharma AK and Sharma AM (eds) Chromosomes in Evolution of Eukaryotic Groups v. 1. CRC Press, Florida, pp 1-114.

John B and Hewitt GM (1970) Interpopulation sex chromosome polymorphism in the grasshopper Podisma pedestris: I. Fundamental facts. Chromosoma 31:291-308.

Jones RN and Rees H (1982) B chromosomes. Academic Press, New York, 254 pp.

King J, Roberts LA, Kearsy MJ, Thomas HM, Jones RN, Huang L, Armstead LP, Morgan WG and King LP (2002) A demonstration of a 1:1 correspondence between chiasma frequency and recombination using a Lolium perenne/Festuca pratensis substitution. Genetics 161:307-314.

Nei M (1977) F-statistics and analysis of gene diversity in subdivided populations. Ann Hum Genet 41:225-233.

Nei M and Chesser RK (1983) Estimation of fixation indices and gene diversities. Ann Hum Genet 47:253-259.
Remis MI (1989) Cytogenetic studies in Sinipta dalmani (Acrididae). I. Effects of pericentric inversion on chiasma conditions. Caryologia 42:285-294.

Remis MI (1990) Cytogenetic studies in Sinipta dalmani (Orthoptera, Acrididae). II. Effects of centric fusions on chiasma frequency and distribution. Génetique, Sélection, Évolution 22:263-272.

Remis MI (1993) Effects of chromosome rearrangements on sperm formation in Sinipta dalmani (Orthoptera, Acrididae). Caryologia 93:321-328.

Remis MI (1997) Cytogenetic studies in Sinipta dalmani (Acrididae). III. Pericentric $\mathrm{M}_{4}$ inversion affecting morphological traits. J Genetics 76:25-32.

Remis MI, Pensel S and Vilardi JC (2000) Multivariate analysis of male mating success on morphometric traits and chromosome dosage in the grasshopper Sinipta dalmani. Heredity $84: 548-554$

Remis MI (2002) Differential adult survival and phenotype variation in the chromosomally polymorphic grasshopper Sinipta dalmani (Orthoptera, Acrididae). Hereditas 136:155-8.

Pensel S and Remis MI (2007) Female mating success depends on body size in the grasshopper Sinipta dalmani (Acrididae). Ann Entomol Soc Am 100:283-288.

Vaio ES, Goñi B and Rey C (1979) Chromosome polymorphism in populations of the grasshopper Trimerotropis pallidipennis from southern Argentina. Chromosoma 71:371-386.

Weissman DB (1976) Geographical variability in the pericentric inversion system of the grasshopper Trimerotropis pallidipennis. Chromosoma 55:325-347.

White MJD (1951a) Structural heterozigosity in natural populations of the grasshopper Trimerotropis sparsa. Evolution 5:376-394.

White MJD (1951b) A cytological survey of the wild populations of Trimerotropis and Circotettix (Orthoptera, Acrididae). II. Racial differentiation in Trimerotropis sparsa. Genetics 36:31-53.

White MJD and Morley FHW (1955) Effects of pericentric rearrangements on recombination in grasshopper chromosomes. Genetics 40:604-619.

Wright S (1951) The genetical structure of populations. Ann Eugen 15:323-354.

Associate Editor: Yatiyo Yonenaga-Yassuda 